\title{
PERAJANG MEKANIK KRIPIK
}

\author{
Sartono Putro \\ Jurusan Teknik Mesin Universitas Muhammadiyah Surakarta \\ Jl.A. Yani Tromol Pos 1 Pabelan Kartasura
}

\begin{abstract}
ABSTRAK
Proses pembuatan kripik tempe dengan perajangan manual mempunyai banyak kelemahan yaitu waktu proses lama, tebal sayatan tidak bisa seragam, permukaan sayatan bergelombang. Perajangan dengan penyayatan manual dapat digantikan menggunakan perajang mekanik yang prinsip kerjanya berdasarkan mekanisme gerak engkol peluncur dengan pemotong sirkel (circle cutter). Penelitian ini bertujuan mencari cutting speed dan feeding speed yang optimum pada pemotongan tempe menjadi kripik tempe dengan ketebalan tertentu. Penelitian dilakukan dengan membuat alat perajang mekanik yang menggunakan prinsip kerja mekanisme engkol peluncur, circle cutter diputar oleh sebuah motor listrik yang dapt diatur putarannya dengan mengganti pulley transmisi. Sedangkan putaran engkol yang merupakan gerak feeding diputar oleh sebuah motor listrik yang berbeda. Hasil penelitian menunjukkan bahwa grafik hubungan antara cutting speed dan kuantitas sayatan menunjukkan bahwa peningkatan cutting speed menghasilkan peningkatan kuntitas sayatan. Percobaan dengan lima variasi kecepatan cutting speed mendapatkan hasil kualiatas sayatan yang sama yaitu secara visual permukaan keping hasil sayatan halus, sedangkan kuantitas terbesar dicapai pada cutting speed $19.927 \mathrm{~mm} / \mathrm{s}$. Diperkirakan kuntitas hasil keping sayatan akan terus meningkat dengan ditingkatkannya cutting speed. Percobaan dihentikan sampai cutting speed $19.927 \mathrm{~mm} / \mathrm{s}$ karena muncul serpihan sayatan yang berbentuk slurry dan mengotori sekeliling alat. Hasil yang optimum pada penelitian ini dicapai pada cutting speed $18.394 \mathrm{~mm} / \mathrm{s}$ dengan kuantitas sayatan 11 keping, pada kondisi ini serpihan sayatan belum mengganggu operasional. Ukuran bahan tempe yang disayat memiliki ketebalan $20 \mathrm{~mm}$, bila hasil sayatan dibuat setebal 1,5 mm, maka satu buah bahan tempe kotak akan dihasilkan sayatan, $\frac{20}{1,5} \approx 13$ keping.
\end{abstract}

\section{Kata kunci: Kripik, Perajang mekanik, Cutting speed, Feeding speed}

\section{PENDAHULUAN}

Kendala yang dihadapi industri kecil tempe kripik saat ini adalah masalah perajangan. Pembuatan kripik tempe dilakukan dengan membuat sayatan tempe secara manual dengan ketebalan sekitar 2 $\mathrm{mm}$. Bahan kripik adalah tempe berbentuk kotak ukuran $20 \times 8 \times 2 \mathrm{~cm}$ yang kemudian disayat dengan ukuran $20 \times 8 \times 0,2 \mathrm{~cm}$. Satu orang perajang yang telah terampil rata-rata hanya mampu merajang 10 kotak per jam. Bila kapasitas produksi industri kecil $125 \mathrm{~kg}$ kedelai yang menghasilkan 625 buah tempe kotak, maka diperlukan waktu perajangan $\frac{625}{10}=62,5 \mathrm{jam}$ untuk satu orang perajang. Perajangan yang dilakukan selama ini mempunyai banyak kelemahan, selain waktu proses yang besar kelemahan lainnya adalah: 
1. Tebal sayatan tidak bisa seragam

2. Permukaan sayatan tidak rata (bergelombang)

3. Banyak membuang bahan baku tempe, akibat tebal sayatan yang tidak seragam maka satu tempe kotak yang seharusnya menjadi 10 keping, ratarata hanya menjadi 8 keping.

\section{TINJAUN PUSTAKA}

Perajangan kripik tempe dengan cara penyayatan manual dapat digantikan menggunakan perajang mekanik yang prinsip kerjanya berdasarkan mekanisme gerak engkol peluncur dengan circle cutter (Putro dan Subroto 2002). Untuk dapat menerapkan alat potong dengan prinsip gerak engkol peluncur pada perajangan kripik tempe harus diketahui perbandingan kecepatan potong (cutting speed) dan kecepatan pemakanan (feeding speed).

Dengan demikian dapat dirumuskan permasalahannya adalah penentuan pasangan yang optimum antara cutting speed dan feeding speed mengingat karakteristik tempe berbeda dari benda kerja lain seperti kayu dan logam yang telah banyak diteliti mengenai sifat mekanisnya.

Proses perajangan kripik dengan penyayatan manual dapat diperlihatkan pada Gambar 1.

Prinsip kerja perajang mekanik yang dibuat adalah mengumpankan tempe pada circle cutter, pada proses ini proses penyayatan dilakukan dengan gerak pisau yang melingkar. Cutting speed untuk circle cutter dapat dihitung menggunakan persamaan berikut.

$$
\begin{aligned}
& \mathrm{v}=\frac{\pi \times \mathrm{d} \times \mathrm{n}}{1000} \mathrm{~m} / \text { menit } \rightarrow \mathrm{n}=\frac{\mathrm{v} \times 1000}{\pi \times \mathrm{d}} \mathrm{rpm} \\
& \mathrm{V} \quad=\text { kecepatan potong } \\
& \mathrm{d} \quad=\text { diameter pisau } \\
& \mathrm{n} \quad=\text { putaran pisau }
\end{aligned}
$$

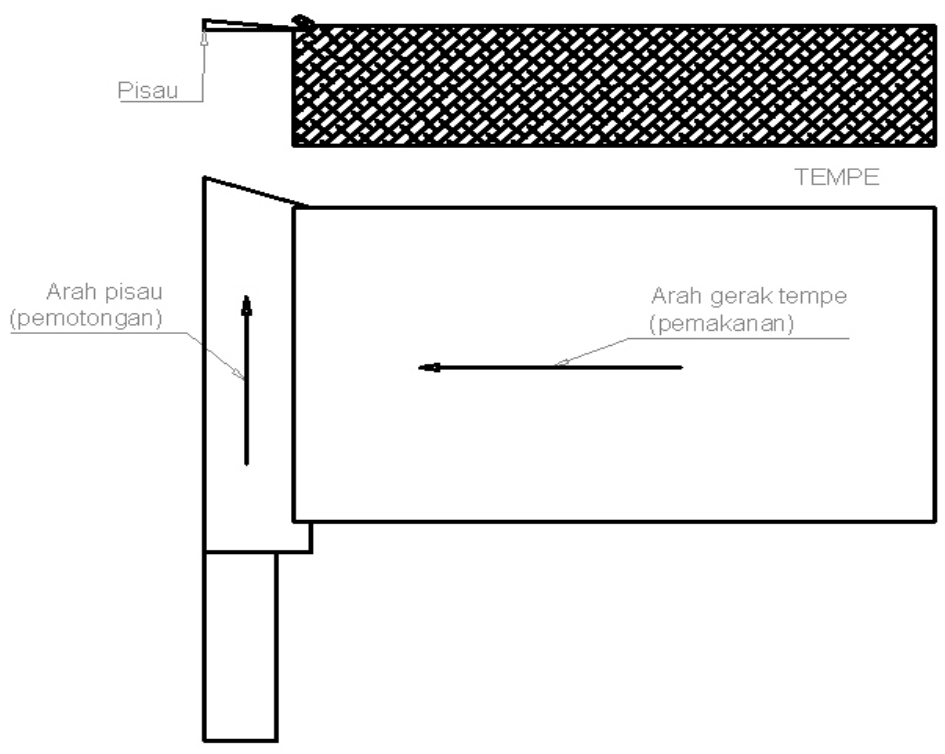

Gambar 1. Proses penyayatan kripik secara manual 


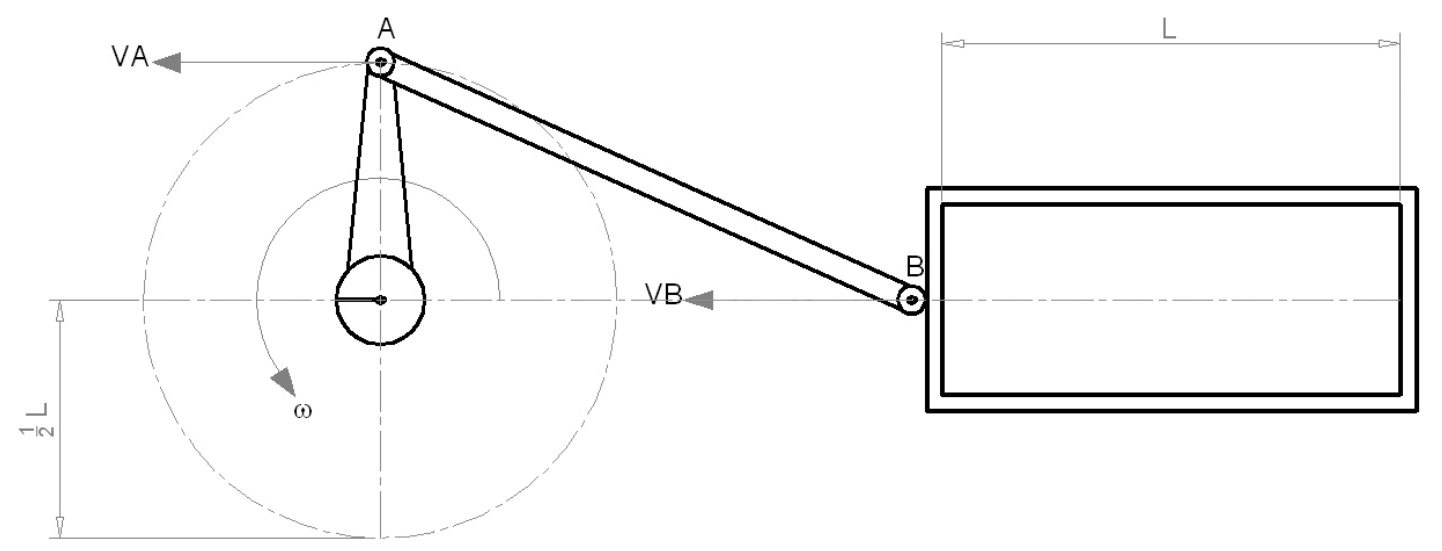

Gambar 2. Diagram kinematik mekanisme engkol peluncur

Feeding speed merupakan kecepatan pengumpanan tempe pada circle cutter, mekanisme proses ini menggunakan prinsip gerak engkol peluncur. Penentuan feeding speed dihitung menggunakan Persamaan Engkol Peluncur. Jari-jari engkol ditentukan dengan panjang benda kerja $l$ yang akan disayat. Batang penghubung berfungsi menghubungkan peluncur dengan jari-rari engkol. Dengan demikian apabila engkol berputar satu putaran, maka peluncur yang merupakan kotak pengumpan akan bergerak maju dan mundur. Gerak maju adalah gerak pemakanan dan gerak mundur merupakan gerak kembali atau gerak tanpa pemakanan. Mekanisme engkol peluncur diperlihatkan pada Gambar 2 dihitung dengan persamaan sebagai berikut.

$$
\begin{aligned}
& \mathrm{V}_{\mathrm{A}}=\omega \times \mathrm{R} \\
& \mathrm{V}_{\mathrm{B} / \mathrm{A}}=\mathrm{V}_{\mathrm{B}} \rightarrow \mathrm{V}_{\mathrm{A}} \cdot \mathrm{V}_{\mathrm{B}}=\mathrm{V}_{\mathrm{A}} \mapsto \mathrm{V}_{\mathrm{B} / \mathrm{A}} \\
& \mathrm{V}_{\mathrm{A}}=\text { kecepatan linier titik } \mathrm{A} \\
& \mathrm{V}_{\mathrm{B}}=\text { kecepatan titik } \mathrm{B} \text { (peluncur) } \\
& \mathrm{V}_{\mathrm{B} / \mathrm{A}}=\text { kecepatan relatif titik } \mathrm{B} \text { terhadap } \\
& \text { titik A } \\
& \omega=\text { kecepatan sudut } \mathrm{R}
\end{aligned}
$$

Penelitian ini bertujuan untuk mendapatkan cutting speed dan feeding speed yang optimum pada pemotongan tempe menjadi kripik tempe dengan ketebalan tertentu. Dengan diketahuinya cutting speed dan feeding speed yang optimum untuk perajangan kripik tempe, maka dapat diterapkan untuk pembuatan model perajang mekanik kripik tempe. Perajang mekanik kripik tempe yang dihasilkan merupakan alat produksi untuk industri kripik tempe yang sebelumnya tidak ada. Penggunaan perajang mekanik kripik tempe dengan berbagai kelebihan dibanding cara produksi yang selama ini dikenal akan dapat memberdayakan pengusaha kecil kripik tempe dengan jalan menekan ongkos satuan produksi.

\section{METODOLOGI PENELITIAN}

1. Variabel penelitian yang digunakan

a. Cutting speed, yaitu putaran circle cutter.

b. Feeding speed, adalah kecepatan pengumpanan tempe ke circle cutter. Pada penelitian ini feeding speed dijadikan variabel bebas, yang besarnya ditentukan $120 \mathrm{rpm}$.

c. Deep of cutting, pada penelitian ini merupakan variabel bebas dan besarnya ditentukan 1,5 $\mathrm{mm}$.

2. Peralatan yang dipergunakan untuk penelitian ini adalah perajang mekanik seperti yang diperlihatkan pada Gambar 6 yang dibuat dengan cara sebagai berikut. 
a. Membuat circle cutter dari baja karbon tinggi agar diperoleh ketajaman yang baik. Bahan baja karbon tinggi dapat diperoleh dengan menggunakan gergaji sirkel yang ada dipasaran (biasanya untuk memotong kayu). Selanjutnya dibuat flens pemegang pisau, flens dibuat dari alumunium untuk mendapatkan ketegaran yang besar tetapi ringan. Hal ini diperlukan karena flens akan dipasang pada sebuah poros yang berputar. Untuk mendapatkan cutting speed yang dikehendaki, poros diputar menggunakan motor listrik dengan transmisi pulley belt. b. Membuat peluncur berbentuk kotak yang berfungsi sebagai pemegang tempe dan mengumpankan pada pisau yang berputar. Karena fungsinya sebagai pemegang bahan (tempe), maka bahan peluncur dipilih dari alumunium tuang agar tahan terhadap karat. Peluncur dihubungkan dengan piringan engkol yang berputar dengan rasio putaran tertentu terhadap putaran circle cutter. Dengan demikian peluncur dapat bergerak majumundur dengan panjang langkah sesuai jari-jari engkol.

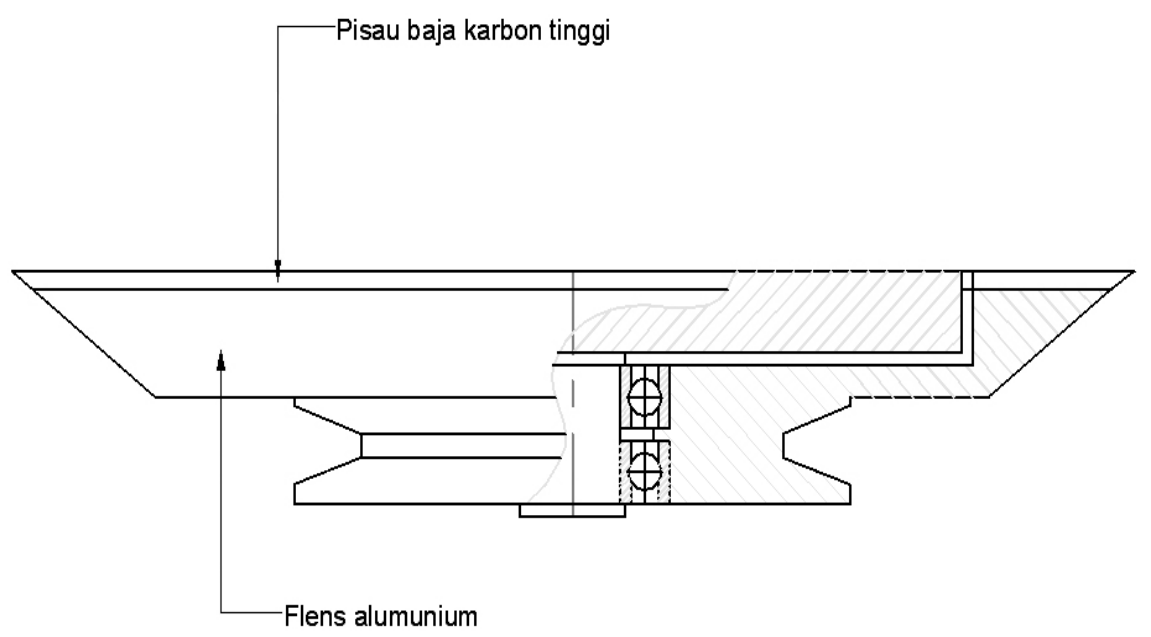

Gambar 3. Circle cutter

Data circle cutter:

- Diameter circle cutter

- Diameter pulley poros circle cutter (driven)

- Diameter pulley motor (driven)

- Motor listrik 1/4 HP / 1450 rpm satu fasa.
: $202 \mathrm{~mm}$

: $100 \mathrm{~mm}$

: $50,75,100,120,130 \mathrm{~mm}$ 


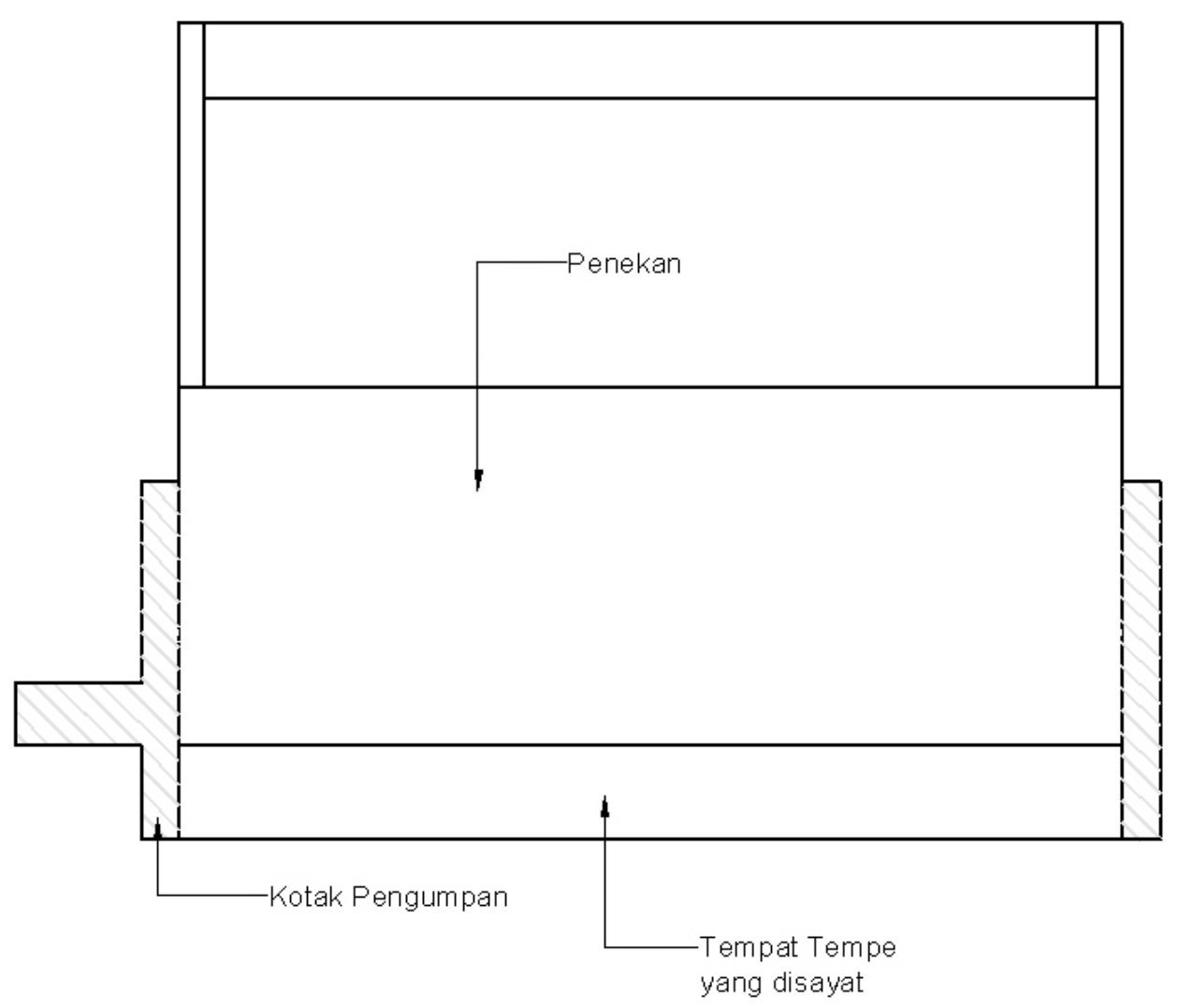

Gambar 4. Kotak pengumpan

Data feeding unit:

- Dimensi kotak pengumpan $\mathrm{p} \times 1 \times \mathrm{t}=200 \times 80 \times 80 \mathrm{~mm}$

- Rasio pulley motor (driver) dan pulley roda engkol (driven) $=1: 12$.

- Motor listrik 1/4 HP / 1440 rpm satu fasa.

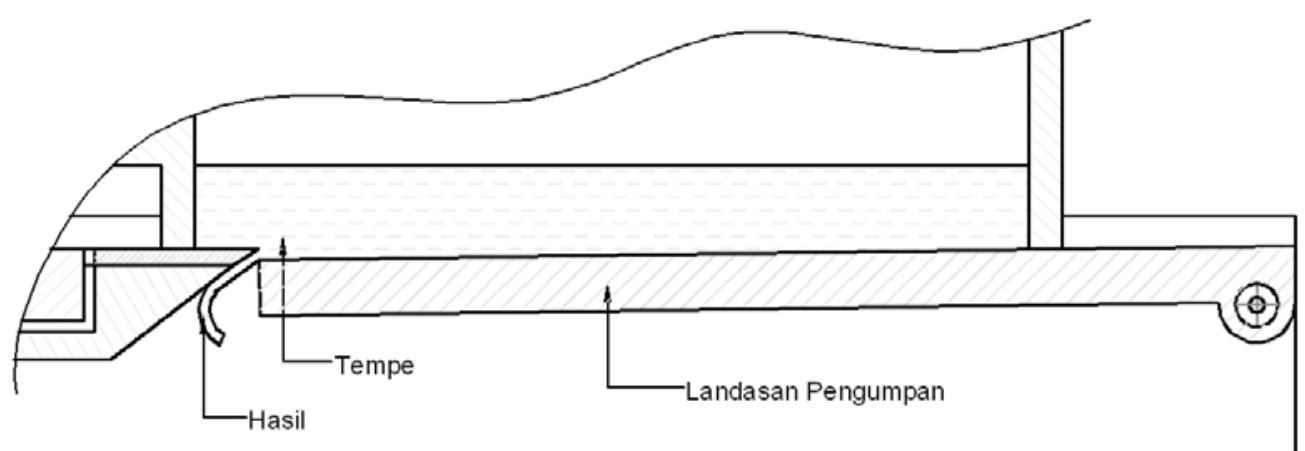

Gambar 5. Landasan pengumpan 


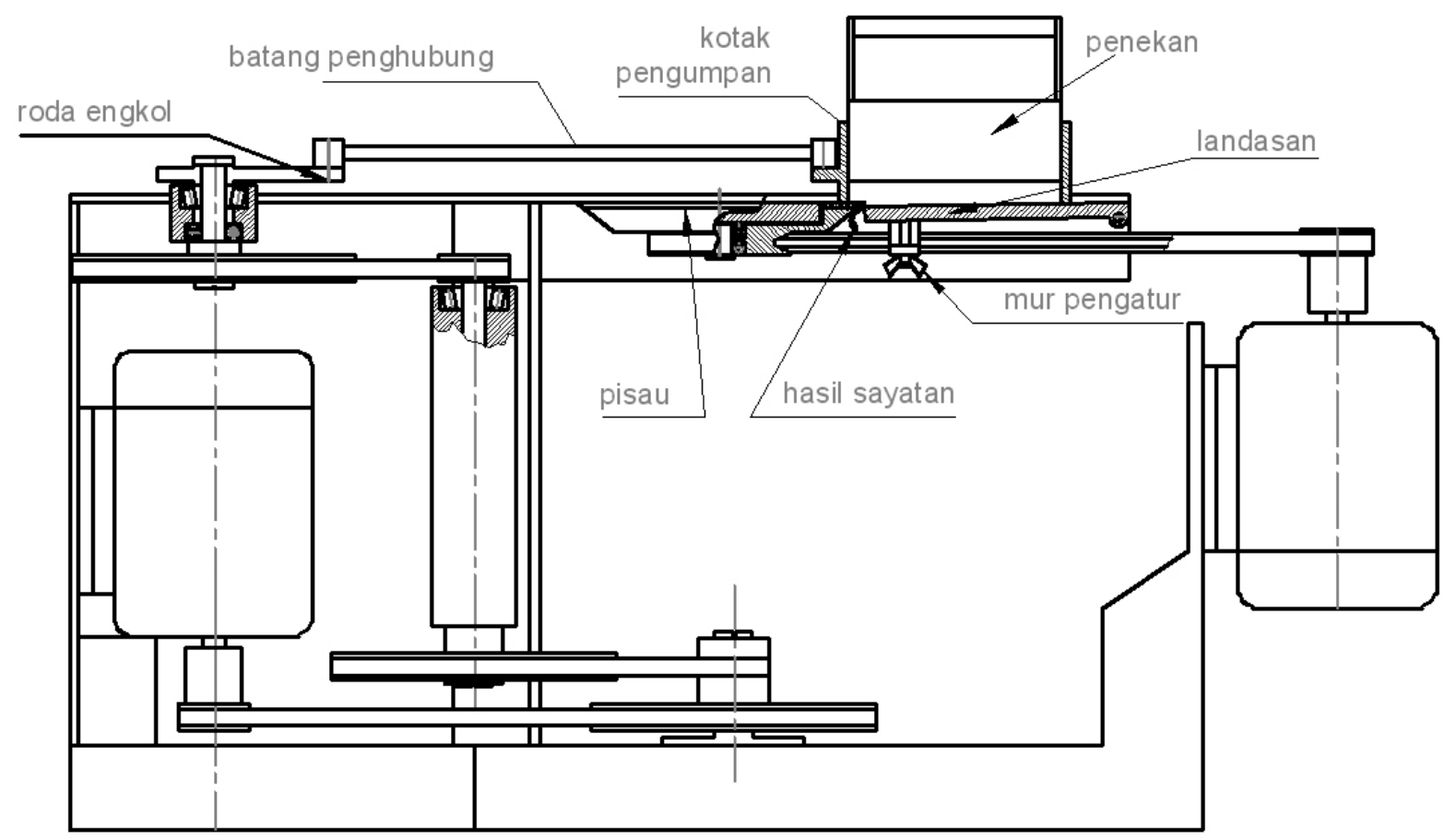

\section{Gambar 6. Perajang mekanik kripik tempe untuk penentuan pasangan kecepatan potong dan kecepatan pemakanan.}

c. Membuat landasan untuk gerak maju-mundur peluncur, gerak maju merupakan gerak pemakanan dan mundur merupakan gerak balik. Landasan dibuat agar mampu membuat permukaan bawah tempe mempunyai jarak terhadap garis mata pisau. Jarak (offset) yang ditimbulkan merupakan tebal irisan yang akan dihasilkan. Dengan demikian ketebalan hasil sayatan dapat dipilih dengan mengatur jarak tersebut.

3. Tahapan Penelitian

a. Memotong tempe untuk membentuk tempe kotak dengan ukuran panjang $200 \mathrm{~mm}$, lebar $80 \mathrm{~mm}$ dan tebal 20 $\mathrm{mm}$.

b. Menghidupkan motor penggerak cutter circle, dan motor penggerak feeding.

c. Mengukur putaran motor penggerak cutter circle, dan motor penggerak feeding menggunakan tachometer. d. Mematikan motor penggerak cutter circle, dan memasang tempe kotak pada kotak pengumpan.

e. Menghidupkan motor penggerak roda engkol feeding, dan menampung hasil sayatan.

f. Mencatat jumlah dan kualitas visual hasil sayatan.

g. Mengganti pulley motor penggerak cutter circle untuk mendapatkan variasi cutting speed.

$h$. Mengulang percobaan sebanyak tiga kali untuk setiap variasi putaran cutter circle.

\section{HASIL DAN PEMBAHASAN}

Hasil perhitungan kecepatan pemotongan (cutting speed) dan kecepatan pemakanan (feeding) ditabelkan sebagai berikut. 
Tabel 1. Hasil perhitungan cutting speed dan feeding speed

\begin{tabular}{cccccc}
\hline No & $\begin{array}{c}\text { Putaran Engkol } \\
\text { Feeding } \\
(\mathrm{rpm})\end{array}$ & $\begin{array}{c}\text { Kecepatan } \\
\text { Feeding } \\
(\mathrm{mm} / \mathrm{s})\end{array}$ & $\begin{array}{c}\text { Diam. Pulley } \\
\text { Motor Peng. } \\
\text { Cutter Circle }\end{array}$ & $\begin{array}{c}\text { Putaran } \\
\text { Cutter Circle } \\
(\mathrm{rpm})\end{array}$ & $\begin{array}{c}\text { Cutting } \\
\text { Speed } \\
(\mathrm{mm} / \mathrm{s})\end{array}$ \\
\hline 1 & 120 & 1256 & $130 \mathrm{~mm}$ & 1885 & 19927 \\
2 & 120 & 1256 & $120 \mathrm{~mm}$ & 1740 & 18394 \\
3 & 120 & 1256 & $100 \mathrm{~mm}$ & 1450 & 15328 \\
4 & 120 & 1256 & $75 \mathrm{~mm}$ & 1088 & 11502 \\
5 & 120 & 1256 & $50 \mathrm{~mm}$ & 725 & 7664 \\
\hline
\end{tabular}

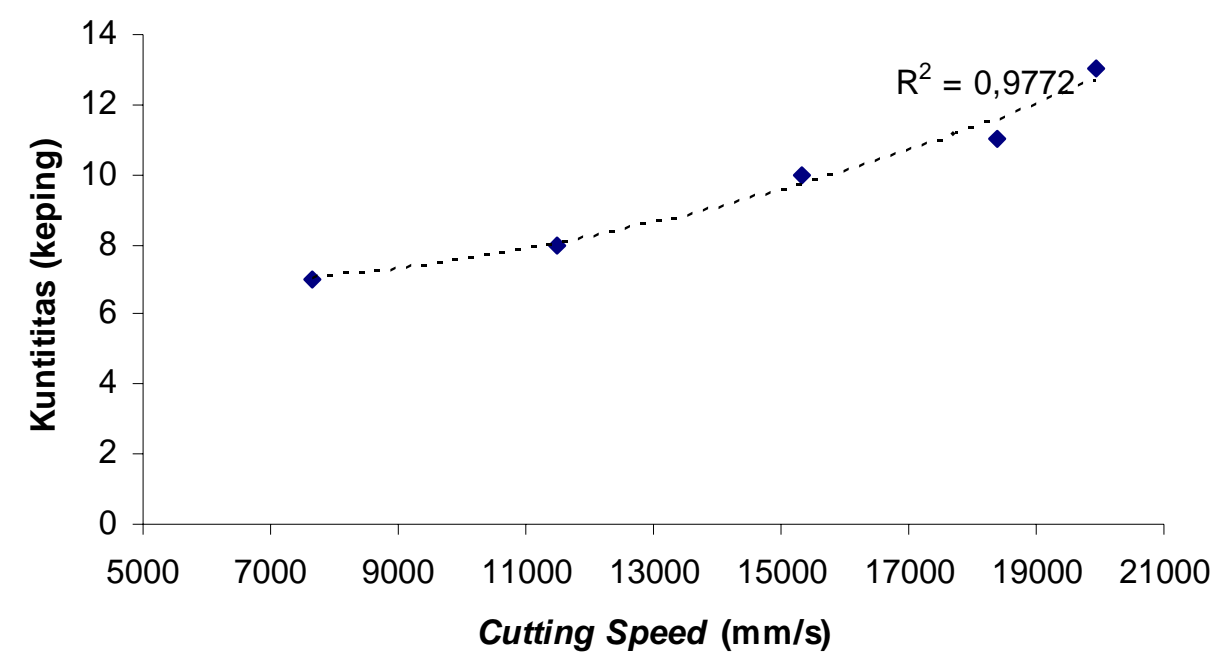

Gambar 8. Hubungan antara cutting speed dengan kuantitas sayatan.

Circle Cutter digerakkan oleh motor listrik dengan putaran $1440 \mathrm{rpm}$ menggunakan transmisi pulley belt. Pulley pada circle cutter berdiameter konstan 100 mm, sedangkan pulley pada motor digunakan lima varian yang dijadikan variabel penelitian. Putaran circle cutter yang merupakan kecepatan potong, dan kecepatan feeding kotak pengumpan dapat dihitung menggunakan persamaan 1. Grafik hubungan antara cutting speed dan kuantitas sayatan menunjukkan bahwa peningkatan cutting speed menghasilkan peningkatan kuntitas sayatan. Hasil lima variasi percobaan yang dilakukan memiliki trend grafik polinomial dengan koefisien korelasi $\left(\mathrm{R}^{2}\right)=0,9772$. Percobaan dengan lima variasi kecepatan cutting speed mendapatkan hasil kualiatas sayatan yang sama yaitu secara visual permukaan keping hasil sayatan halus, sedangkan kuantitas terbesar dicapai pada cutting speed 19.927 $\mathrm{mm} / \mathrm{s}$. 
Diperkirakan kuntitas hasil keping sayatan akan terus meningkat dengan ditingkatkannya cutting speed. Percobaan dihentikan sampai cutting speed 19.927 $\mathrm{mm} / \mathrm{s}$ karena muncul serpihan sayatan yang berbentuk slurry dan mengotori sekeliling alat. Dengan demikian konstruksi alat yang dibuat tidak layak untuk dioperasikan pada cutting speed yang lebih tinggi. Dari ke lima percobaan yang dilakukan didapatkan hasil yang paling optimum pada cutting speed $18.394 \mathrm{~mm} / \mathrm{s}$ dengan kuantitas sayatan 11 keping, pada kondisi ini serpihan sayatan belum mengganggu operasional. Ukuran bahan tempe yang disayat memiliki ketebalan $20 \mathrm{~mm}$, bila hasil sayatan dibuat setebal $1,5 \mathrm{~mm}$, maka satu buah bahan tempe kotak akan dihasilkan sayatan, $\frac{20}{1,5} \approx 13$ keping.

\section{KESIMPULAN DAN SARAN}

Hasil dari pengamatan dan perhitungan dapat disimpulkan bahwa untuk memperoleh hasil perajangan kripik tempe yang paling optimum untuk ketebalan 1,5 $\mathrm{mm}$ dicapai pada pasangan feeding speed $1256 \mathrm{~mm} / \mathrm{s}$ dan $18.394 \mathrm{~mm} / \mathrm{s}$ dengan kuantitas sayatan 11 keping, pada kondisi ini serpihan sayatan belum mengganggu operasional. Pasangan hasil feeding speedcutting speed memiliki putaran roda engkol $120 \mathrm{rpm}$, ini berarti perajang mekanik kripik tempe hasil penelitian mampu membuat sayatan kripik tempe setebal 1,5 mm dengan kecepatan perajangan 7200 keping per jam. Penggunaan perajang mekanik kripik tempe memiliki keunggulan kecepatan sayatan 7200 keping per jam, sementara perajangan manual hanya mampu merajang sebanyak 100 keping per jam per orang.

Berdasarkan hasil percobaan bila ada yang tertarik untuk melanjutkan penelitian ini disarankan untuk meneliti model cutter baru yang dimungkinkan untuk meningkatkan kuntitas sayatan tanpa menimbulkan serpihan slurry yang mengganggu. Variasi bahan sulit disayat secara mekanik misalnya untuk kripik paru dan bahan kerupuk yang lengket dapat diperguakan sebagai variabel penelitian. Dengan tersedianya data untuk bermacam bahan untuk kripik akan membantu pengusaha industri kecil makanan untuk meningkatkan kapasitas dan efisiensi dalam produksinya.

\section{DAFTAR PUSTAKA}

Martin George H., 1985, Kinematika dan Dinamika Teknik, Erlangga, Jakarta.

Putro S., dan Subroto, 2002, Rekayasa Perajang Kripik Tempe Laporan Akhir Pelaksanaan Kegiatan Program Vucer Tahun 2002, Lembaga Pengabdian Pada Masyarakat Universitas Muhammadiyah Surakarta, Surakarta.

Terheijden C. Van, dan Harun, 1986, Alat-alat Perkakas 1, Binacipta, Bandung. 